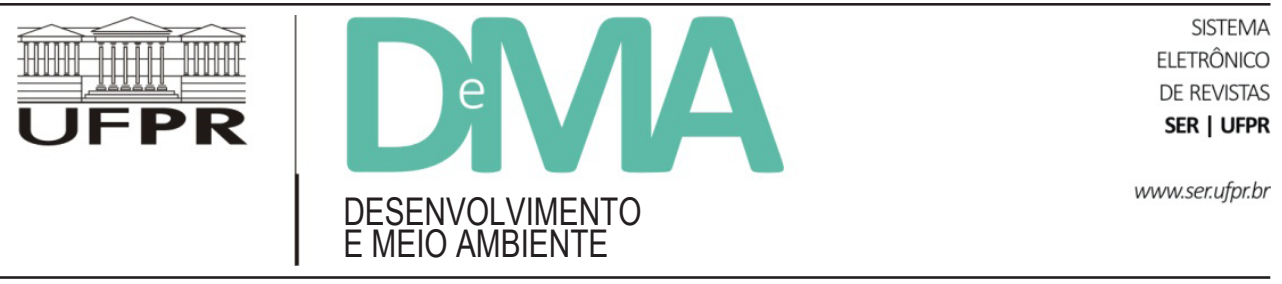

\title{
Transformações nos sistemas de produção familiares diante a implantação do cultivo de dendê na Amazônia Oriental
}

\section{Changes in Family Production Systems on the Implementation of Palm Oil in Eastern Amazonia}

\author{
Edfranklin Moreira da SILVA ${ }^{1 *}$, Lívia de Freitas NAVEGANTES-ALVES ${ }^{2}$ \\ ${ }^{1}$ Universidade Federal do Pará (UFPA), Campus Universitário do Tocantins, Cametá, PA, Brasil. \\ ${ }^{2}$ Programa de Pós-graduação em Agriculturas Amazônicas, Universidade Federal do Pará (UFPA), Belém, PA, Brasil. \\ *E-mail de contato: edfranklin@ufpa.br
}

Artigo recebido em 21 de junho de 2016, versão final aceita em 25 de fevereiro de 2017.

RESUMO: Neste artigo, analisam-se as mudanças nos sistemas de produção familiares ao longo de suas trajetórias produtivas, enfatizando-se as transformações ocorridas em função da implantação da dendeicultura nesses sistemas na Amazônia Oriental. A pesquisa foi realizada no Nordeste Paraense (principal área de expansão de dendezais), onde foram aplicados 162 questionários junto a agricultores familiares integrados às agroindústrias de dendê. Realizou-se também análise retrospectiva em 10 estabelecimentos agrícolas. Como principais resultados, obteve-se a identificação de cinco tipos de sistemas de produção, combinando-se a cultura do dendê com atividades como o cultivo de anuais, sistemas agroflorestais (SAF), pimenta do reino e a criação de bovinos. $\mathrm{Na}$ análise de trajetória, a tipologia revelou três grupos de trajetórias: 1) trajetória das anuais e com tendência à especialização no cultivo do dendezeiro; 2 ) trajetória das perenes (destaque para a pimenta do reino e frutíferas em SAF) e dendê e; 3) trajetória da pecuária e dendê. O que diferenciam as trajetórias são as estratégias desenvolvidas por cada família para garantir sua reprodução social por meio da agricultura. Conclui-se que a implantação da dendeicultura provocou transformações na estrutura, organização e trajetória dos sistemas de produção, mas as mudanças não são apenas práticas. Ocorreram, também, mudanças no campo simbólico, pois o sistema de integração representa, para os agricultores familiares, a "modernidade", por dispor de todo um aparato financeiro e tecnológico o qual culturas tradicionais na região, como a atividade da mandioca, não possuem. Assim, para os agricultores, observou-se que a dendeicultura representa a principal alternativa para o desenvolvimento.

Palavras-chave: trajetórias produtivas; agricultura familiar; dendeicultura; Amazônia.

ABSTRACT: In this article, we analyze the changes in family production systems throughout their productive paths, emphasizing the changes occurred due to the implementation of palm oil in these systems in Eastern Amazon. The survey was conducted in Northeastern Pará (main oil palm expansion area), where 162 questionnaires were applied to family farmers integrated into palm agribusinesses and also a retrospective analysis was held 
in 10 farms. As main results, five types of production systems combining palm culture with other activities, such as annual crops cultivation, agroforestry systems (SAF), black pepper and cattle, were identified. In the trajectory analysis, typology revealed three trajectory groups: 1) the trajectory of annual crops with a tendency to specialization in oil palm cultivation; 2) the trajectory of perennial (highlighting black pepper and fruit in SAF) and palm, and; 3) the trajectory of livestock and oil palm. What differentiates the trajectories are the strategies developed by each family to ensure their social reproduction through agriculture. It was concluded that the implementation of palm culture caused changes in the structure, organization and course of production systems, but the changes are not only practical, but also symbolic, because the system integration represents " modernity " to family farmers, by having all the financial and technological apparatus that traditional cultures in the region, such as cassava, do not. So for farmers this is the main alternative for development.

Keywords: productive paths; family farming; oil palm; Amazon.

\section{Introdução}

A implantação da cultura do dendê (Elaeis guineensis Jacq.) na Amazônia Oriental, com objetivos agroindustriais, iniciou-se da década de 1980 (Muller et al., 1989). No entanto, até os anos 2000, essa cultura não era expressiva em termos de produção e área ocupada. De acordo com o Instituto Brasileiro de Geografia e Estatística (IBGE), a área plantada com dendezeiro no Pará, em 2000, era de 27,6 mil hectares; em 2014, a área plantada subiu para 67,7 mil hectares (IBGE, 2015). Outro dado, levantado pela Associação Brasileira de Palma de Óleo (ABRAPALMA) em 2014, apresenta uma área de aproximadamente 200 mil hectares de dendê plantado no estado.

Esse abrupto crescimento da lavoura de dendê foi fomentado pela criação do Programa Nacional de Produção e Uso de Biodiesel (PNPB), em 2004, e do Programa de Produção Sustentável de Óleo de Palma (PSOP), em 2010 (Nahum \& Malcher, 2012). Críticos a esse processo argumentam que a expansão da dendeicultura na região Nordeste Paraense (NEP) é um novo avanço do agronegócio, o qual reproduz práticas de concentração do acesso à (e do uso da) terra (Backhouse, 2013).

Nesse contexto, os agricultores familiares têm sido estimulados, pelo Poder Público, a participarem do processo de expansão da dendeicultura, por meio dos sistemas de integração. ${ }^{1}$ Para tanto, assinam um contrato pelo qual se comprometem a produzir matéria-prima e a empresa integradora se compromete a comprar a produção. Entende-se aqui como agricultura familiar uma categoria genérica que engloba uma diversidade de formas de organização social da produção que tem como características principais a centralidade da família nas decisões e organização do estabelecimento agrícola e na construção do patrimônio familiar, como explica Wanderley (2009).

Esses agricultores familiares, no Nordeste Paraense, desenvolvem sistemas de produção diversificados, combinando o cultivo de culturas temporárias e permanentes, criação de pequenos animais (principalmente aves e suínos) e bovinos (Conceição, 2002; Hurtienne, 2005) e extrativismo

\footnotetext{
${ }^{1}$ Um debate mais denso sobre os sistemas de integração dendeícola no Pará pode ser observado no trabalho: Vieira, A. C. A "integração” camponesa ao monocultivo de dendê: subordinação e transformação do campesinato amazônico. Dissertação (Mestrado em Agriculturas Familiares e Desenvolvimento Sustentável) - Universidade Federal do Pará, Belém, 2015.
} 
vegetal e animal. Os sistemas de produção são a combinação de atividades produtivas e dos fatores de produção (compreendendo, inclusive, o trabalho familiar), sob organização da família (Brossier, 1987).

A implantação do dendezeiro nesses sistemas produtivos sugere mudanças, uma vez que se trata de uma commodity ocupando uma área (normalmente de 10 hectares) quase seis vezes maior que o tamanho das roças de mandioca (Manihot esculenta), que têm em média 1,5 hectares na região. Torna-se, também, necessário alocar mais mão de obra para o cultivo do dendê, o que poderia comprometer o trabalho em outras parcelas cultivadas, como, por exemplo, as roças de mandioca ou os cultivos consorciados de açaí (Euterpe oleracea), cupuaçu (Theobroma grandiflorum) e cacau (Theobroma cacao).

As mudanças nos sistemas de produção familiares têm sido objeto de estudo por estarem confrontadas com o conceito de reprodução. Este último pode ser entendido como o processo dinâmico de perpetuação de uma entidade coletiva (a família) a partir de transformações e adaptações, considerando sua diversidade e complexidade, a fim de analisar os campos de coerência, tanto internamente como nas suas interconexões recíprocas (Raynaut, 1994).

Nesse sentido, a estrutura e o funcionamento dos estabelecimentos agrícolas refletem ações e projetos (de curto e longo prazo) almejados pelos agricultores familiares. No estudo das trajetórias dos sistemas de produção familiares, pode-se ob- servar que as decisões tomadas pelos agricultores são fortemente guiadas pelo objetivo da reprodução (Rocha \& Almeida, 2013). Segundo Rocha (2016), a reprodução social pode ser vista como um processo que articula a organização dos meios de produção (principalmente terra e trabalho) e sua vinculação com as dinâmicas externas.

O processo de mudança nos estabelecimentos agrícolas familiares é complexo, influenciado pela estrutura, lógica de funcionamento e trajetória dos sistemas de produção (Navegantes-Alves et al., 2012). Para Raynaut (1997), a transformação é condição para a reprodução; uma unidade de produção se perpetua à medida que se modifica. Desse modo, o estudo dessas mudanças deve ter enfoque processual, considerando, além do ponto de partida e a situação atual, as interrelações dos fatores envolvidos com as modificações, bem como seu movimento constante ao longo do tempo (Navegantes-Alves et al., 2012).

Partindo-se dessa compreensão, o objetivo deste artigo é analisar as transformações nos sistemas de produção familiares integrados às agroindústrias de dendê, na região do Nordeste Paraense, por meio da análise de suas trajetórias.

\section{Metodologia}

Este estudo foi realizado na Mesorregião Nordeste Paraense, entre os anos de 2014 e 2015. Foram aplicados 162 questionários ${ }^{2}$ com agricultores familiares produtores de dendê nos Municípios

\footnotetext{
2 A aplicação desses questionários foi realizada com o apoio e participação do grupo de pesquisa e Projeto Agricultura Familiar e Inclusão Social (AFInS). O projeto AFInS é financiado pela Embrapa, sob o título "Integração da Agricultura Familiar na Produção do Dendê no Pará: Possibilidade de Inclusão Social?” A execução do projeto ocorre por meio de parcerias com a Universidade Federal do Pará (UFPA) e Sindicatos Rurais do Nordeste Paraense no período 2014/2017. A pesquisa privilegia: i) agricultores e agricultoras familiares que têm contrato de integração à agroindústria de dendê; ii) jovens que trabalham nos estabelecimentos familiares e como assalariados; e iii) moradores das vilas situadas no entorno dos monocultivos. O sistema agrário, os estabelecimentos (grupos domésticos e sistemas de produção) e as vilas são as principais referências empíricas.
} 
de Acará, Capitão Poço, Concórdia do Pará, Irituia, São Domingos do Capim, Tailândia e Tomé-Açu, com a finalidade de caracterizar seus sistemas de produção. Foi elaborada uma tipologia de sistemas de produção, que revelou cinco tipos de sistemas de produção dendeícola praticados por agricultores familiares. Com o objetivo de compreender as mudanças ocorridas nos sistemas de produção, estudaram-se as trajetórias desses sistemas. Para tanto, escolheram-se dois casos ilustrativos de cada tipo, totalizando 10 estabelecimentos estudados em detalhes. Na Figura 1, pode ser observado todo o procedimento metodológico da pesquisa.

Buscou-se, nesse estudo com os casos ilustrativos, não a representatividade estatística, mas demonstrar as situações que poderiam representar a diversidade de sistemas de produção no NEP. O método utilizado foi a Análise Retrospectiva, formalizado por Moulin et al. $(2004 ; 2008)$. Esse procedimento permitiu analisar mais finamente as mudanças ocorridas nas práticas agrícolas, no uso da terra e na alocação de mão de obra, diante da introdução da dendeicultura. Segundo Navegantes-Alves et al. (2012), que realizou um estudo pioneiro de aplicação da Análise Retrospectiva no Brasil, o exame das trajetórias permite perceber um sentido para as mudanças, uma coerência na evolução dos estabelecimentos agrícolas e, portanto, uma tendência.

Realizaram-se entrevistas históricas (com apoio de um roteiro com questões abertas) junto a atores-chave na região - bons conhecedores da

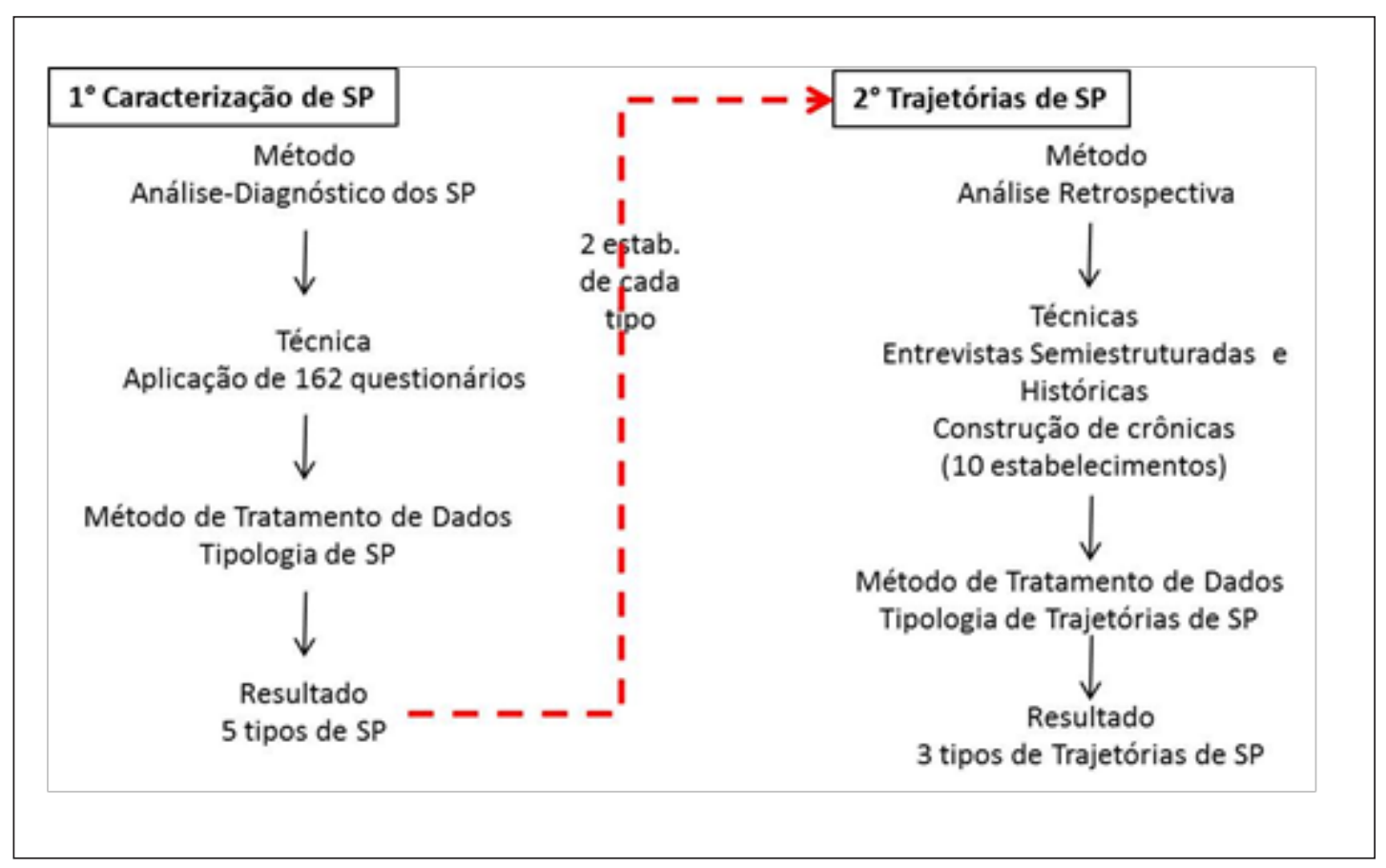

FIGURA 1 - Esquema-síntese da metodologia. SP: Sistema de Produção. FONTE: da pesquisa (2015). Elaborado pelos autores. 
história da região, que vivenciaram o período de chegada das agroindústrias de dendê -, os quais poderiam indicar importantes eventos ocorridos ao longo do tempo, bem como seus efeitos na dinâmica dos sistemas de produção. O objetivo foi identificar os fatos que poderiam influenciar tais transformações.

Para o estudo retrospectivo, realizaram-se entrevistas semiestruturadas com um roteiro de perguntas fechadas e abertas, com as quais se buscou conhecer os fatos históricos ocorridos e a relação destes com o meio envolvente, a fim de prover subsídios à construção das crônicas. ${ }^{3}$ Para facilitar as entrevistas, pedia-se aos agricultores que fizessem um croqui da situação atual do lote, nesse caso, tendo-se como referência o ano de 2015. Depois, eles faziam outro croqui do período em que chegaram ao estabelecimento. Os croquis foram fundamentais para compreender as evoluções das parcelas nos sistemas de produção.

Com o estudo retrospectivo, percebeu-se que uma mesma trajetória poderia direcionar sistemas de produção diferentes, por isso, foi realizada uma tipologia de trajetórias. Assim como no estudo de Navegantes-Alves et al. (2012), a trajetória entrou na chave tipológica, tendo em vista o objetivo de compreender as transformações ocorridas ao longo do tempo. Nesse contexto, as próprias mudanças foram um elemento de diferenciação. A tipologia das trajetórias dos estabelecimentos agrícolas foi elaborada por meio do método tipológico apresentado por Capillon (1993), que permitiu identificar e comparar as transformações nos sistemas de produção de agricultores integrados às agroindústrias de dendê na região.

\section{Resultados e discussão}

\subsection{A diversidade de sistemas de produção} familiares integrados à agroindústria do dendê

Identificaram-se cinco tipos de sistemas de produção familiares integrados à agroindústria do dendê no Nordeste Paraense: 1) T1 - dendê principal; 2) T2 - culturas anuais e dendê; 3) T3 - frutíferas e dendê; 4) T4 - pimenta do reino e dendê e; 5) T5 - pecuária e dendê. Esses sistemas de produção podem ser caracterizados como diversificados, haja vista a variabilidade de 4 a 14 atividades (agrícola, criação e/ou extrativa) realizadas nos lotes, conforme se observa na Tabela 1. Adiversidade produtiva é uma característica da agricultura familiar na Amazônia Paraense, como destacam vários estudos como Walker et al. (1998), Conceição (2002), Hurtienne (2005), Rocha (2016), entre outros.

Em outros termos, Brondízio (2006) argumenta que os sistemas de produção familiares se baseiam na coexistência de atividades intensivas e extensivas, na tentativa de minimizar o risco e consolidar os estabelecimentos agrícolas e, assim, expandir as atividades voltadas para o mercado. Nesse sentido, o dendê, para os agricultores familiares, é a possibilidade de uma atividade perene, que permita expandir o acesso ao mercado e a ter renda para consumir o que não é produzido nos lotes.

Em se tratando da quantidade de membros da família, verificou-se que o grupo que tem o cultivo do dendê como atividade principal tem o menor número de componentes do grupo doméstico, e que o grupo em que predomina a pimenta do reino

\footnotetext{
${ }^{3}$ Essas são as representações de um determinado estabelecimento agrícola, de acordo com fatos agrupados em períodos, segundo sua ocorrência cronológica.
} 
TABELA 1 - Características gerais dos sistemas de produção familiares integrados às agroindústrias de dendê no Nordeste Paraense: componentes da família, quantidade de atividades praticadas e uso da terra.

\begin{tabular}{|c|c|c|c|c|c|c|c|c|}
\hline \multirow[b]{2}{*}{ TIPOS } & \multirow{2}{*}{$\begin{array}{l}\text { COMP. } \\
\text { FAMÍLIA }\end{array}$} & \multirow{2}{*}{$\begin{array}{l}\text { QTD. } \\
\text { ATV. }\end{array}$} & \multicolumn{6}{|c|}{ USO DA TERRA (HECTARES) } \\
\hline & & & Floresta & Capoeira & Dendê & $\begin{array}{c}\text { Frutas/Pimenta } \\
\text { do reino }\end{array}$ & Anuais & Pastagem \\
\hline Culturas anuais e dendê & 5 & 11 & 8,2 & 13,2 & 9,9 & 1,2 & 1,5 & 1,8 \\
\hline Frutíferas e dendê & 5 & 12 & 13,4 & 16,2 & 10,8 & 4,0 & 0,9 & 0,0 \\
\hline Pecuária e dendê & 5 & 14 & 8,9 & 14,5 & 10,7 & 1,4 & 1,1 & 14,0 \\
\hline
\end{tabular}

FONTE: da pesquisa (2015). Elaborado pelos autores.

e dendê (T4) tem o maior número de membros na família. Esses dados demonstram que, para o $\mathrm{T} 4$, parece haver maior disponibilidade de mão de obra, entretanto, outros fatores devem ser observados, como idade e o gênero dessas pessoas. Os demais grupos apresentaram cinco membros no grupo doméstico. Verificou-se que a mão de obra familiar predomina, mas, com a implantação do dendê, tem-se aumentado a contratação de terceiros para os serviços mais penosos, como a colheita dos cachos de dendê.

Os dados levantados aqui sobre os componentes do grupo familiar corroboram o estudo realizado por Mota (2014), com 269 famílias agricultoras no Nordeste Paraense. Nesse estudo, a autora identificou a existência de sete arranjos familiares, em que predominavam grupos domésticos do tipo nuclear e uma forte relação entre os grupos extensos com a disponibilidade dos recursos naturais.

A maior área plantada com a cultura do dendê foi verificada no grupo pimenta do reino e dendê (13,3 hectares) e a menor, no somente dendê $(9,4$ hectares), conforme se observa na Tabela 1. Mas a média de áreas é de 10 hectares, pois a política de crédito (Pronaf Eco Dendê) financia até essa faixa. $\mathrm{O}$ que acontece para que alguns grupos apresentem uma área maior que o limite financiado é que os agricultores dividem a terra com um dos filhos mais velhos por meio de um contrato de comodato, o qual possibilita que a família realize outro financiamento para o dendê no nome de outro membro da família. Verificou-se, também, que o grupo dendê principal não possui área de roça; assim, esses não produzem a farinha de mandioca, produto básico da alimentação das famílias rurais no Nordeste Paraense. Vários estudos têm apresentado como resultado o abandono das culturas anuais em função da implantação da dendeicultura nos lotes. Segundo o estudo realizado por Mota et al. (2015) na mesma região, $24 \%$ dos agricultores não têm roças nos seus estabelecimentos, sob o argumento de que necessitam se dedicar exclusivamente ao dendê. Na mesma perspectiva, Sampaio (2014) realizou um estudo de caso no Município de Tomé-Açu, onde $22 \%$ dos agricultores por ele entrevistados não cultivam mais culturas alimentares.

No entanto, esse grupo dendê principal apresenta uma importante área de frutas, normalmente de açaí, que foi plantada às margens dos igarapés a partir de plantas originárias da área. A menor área de anuais foi verificada no grupo em que predomina a pimenta do reino e o dendê, por ser uma área bem 
abaixo da média da região ( 1,5 hectares). Isso indica que o cultivo de anuais é apenas para alimentação da família, diferentemente do que ocorre no grupo predominante em anuais e dendê, que produz mandioca para fabricação de farinha, com objetivo de vender nos mercados locais.

Quase todos os grupos apresentam área de pastagem, com exceção do grupo predominante em frutas e dendê. Apesar disso, verificou-se que apenas o grupo predominante em pecuária e dendê cria bovino. $\mathrm{O}$ fato de muitos agricultores terem área de pasto indica que uma das direções do projeto familiar seria criar bovino, visto que os custos para produzir esses animais são mais baixos, bem assim a mão de obra demandada para essa atividade (Veiga et al., 2004).

\subsection{As trajetórias dos sistemas de produção}

Em se tratando das trajetórias dos sistemas de produção familiares, verificou-se que uma mesma trajetória produtiva possibilitava sistemas de produção diferentes, como a trajetória Perenes/ Dendê, na qual se verificam sistemas de produção predominantemente frutíferos e/ou pimentais, assim como a trajetória Anuais/Dendê, com sistemas de produção predominantes em anuais, com aqueles que abandonaram as anuais se especializando na dendeicultura. Nesse sentido, observou-se uma nova tipologia determinada pela trajetória. Assim, uma trajetória permitiu chegar à conformação de sistemas de produção diferentes.

Para efeito de síntese, foi realizada a tipologia das trajetórias dos sistemas de produção integrados à agroindústria de dendê, bem como construídas crônicas de cada um dos tipos. Os grupos típicos identificados no estudo foram: 1) Trajetória Pecuária/Dendê (TPD) - $21 \%$ dos entrevistados; 2 ) Trajetória Anuais/Dendê (TAP) - 66\% dos entrevistados e; 3) Trajetória Perenes e Dendê (TPED) - 13\% dos entrevistados. Esses três tipos de trajetórias de sistemas de produção apresentam fases de mudanças bem diferenciadas entre si, conforme pode ser observado na Tabela 2. Cada fase corresponde a uma forma de organização e condução das atividades desenvolvidas nos sistemas de produção e direcionadas pelo projeto da família (Navegantes-Alves et al., 2012).

TABELA 2 - Síntese das fases de cada tipo de trajetória de sistema de produção familiares integrados à agroindústria de dendê no Nordeste Paraense.

\begin{tabular}{|c|c|c|c|}
\hline Tipos $\quad$ Fases & $\begin{array}{l}\text { Fase 1: início do sistema de } \\
\text { produção }\end{array}$ & Fase2: estabilização/crise de projetos & Fase 3: implantação do dendê \\
\hline $\begin{array}{l}\text { Trajetória } \\
\text { Pecuária } \\
\text { Dendê }\end{array}$ & $\begin{array}{l}\text { Formação da pastagem e crescimento } \\
\text { da pecuária }\end{array}$ & Estabilização da pecuária & Pecuária/Dendê \\
\hline $\begin{array}{l}\text { Trajetória } \\
\text { Anuais } \\
\text { Dendê }\end{array}$ & Realização de grandes roças & $\begin{array}{l}\text { Contradições no mercado da farinha de } \\
\text { mandioca e crise do sistema técnico de corte } \\
\text { e queima }\end{array}$ & Anuais/Dendê \\
\hline
\end{tabular}

* SAF: Sistemas Agroflorestais.

** Forma usada pelos agricultores familiares no Nordeste Paraense para identificar a parcela do cultivo de pimenta do reino.

FONTE: da pesquisa (2015). Elaborado pelos autores. 
A Fase 1 representa o início dos sistemas de produção. A maioria (51\%) dos agricultores familiares chegou ao estabelecimento a partir de 2001. Portanto, recentemente, visto que se encontram na área de colonização mais antiga do Estado do Pará. Outros 28\% se instalaram em seus lotes entre 1991 e 2000 , e $21 \%$, antes de 1990 . Normalmente, na chegada, os agricultores realizavam roças de culturas anuais para produção da própria alimentação e comercialização de excedente.

Verificou-se que, desde o início, os agricultores já tinham seus projetos agrícolas bem definidos. $\mathrm{O}$ tipo TPD (Pecuária/Dendê), na chegada ao lote, derrubou a floresta e plantou anuais para poder ir formando os pastos. As anuais, nesse sentido, foram estratégicas para preparar a área para as pastagens. O período da chegada para o tipo TAD (Anuais/Dendê) representou o período da realização de grandes roças, onde áreas de 3 a 5 hectares de florestas eram derrubadas e queimadas para plantação de arroz (Oryza sativa), feijão-caupi (Vignaun guiculata), mandioca e algumas cucurbitáceas (abóbora, abobrinha de moita, melancia, pepino...). Para o tipo TPED (Perenes/Dendê), no início, as roças eram feitas para o consumo da família e para preparar a área para as perenes, normalmente compreendendo pimenta do reino (Piper nigrum) e frutíferas (cacau, cupuaçu e açaí).

A Fase 2 representa a estabilização dos projetos agrícolas para os tipos de trajetórias TPD e TPED, enquanto o tipo TAD tem profundas dificuldades, pois tem sua produção baseada na feitura da farinha de mandioca para comercialização no mercado regional. Para esse último grupo, o mercado é bastante incerto, visto que a comercialização é realizada por meio de atravessadores, e as receitas não conseguem cobrir os custos.

No entanto, a vulnerabilidade do grupo TAD possui um grau menor, pois parte do que produzem é consumida pela família, de modo que não dependem do mercado para atender às necessidades básicas alimentares; mesmo a receita sendo baixa, eles mantêm essa estratégia de vivência, nos termos estabelecidos por Ellis (2000). Além disso, deve-se considerar também que a prática de caça e pesca é bem comum e importante (52\% praticam), o que contribui para a parte proteica da dieta das famílias. O que vai determinar a mudança de estratégia são as crises no sistema técnico (corte e queima) e no sistema de cultivo da mandioca (principalmente problemas fitossanitários), que contribuirão para o ambiente favorável à dendeicultura, como será discutido adiante.

Na Fase 3, verifica-se a implantação do dendê nos lotes dos agricultores familiares. A dendeicultura modifica a trajetória dos sistemas de produção. Aqueles que seguiam um caminho baseado na pecuária, no cultivo de anuais e nas culturas perenes para sua estabilização optam pela cultura do dendê como uma estratégia que pode contribuir para a consolidação dos estabelecimentos. Isso é o projeto da família, fruto de uma construção histórica e contextualizada, como explica Navegantes-Alves et al. (2012). Nesse sentido, verifica-se, na Fase 3, as seguintes trajetórias: Pecuária/Dendê, Anuais/ Dendê e Perenes/Dendê.

\subsubsection{Trajetória Pecuária/Dendê}

Com o objetivo de ilustrar, foi elaborada uma representação sintética do tipo de trajetória Pecuária/Dendê (Figura 2), no qual é possível observar as fases do sistema de produção. Apenas os fatos externos que apresentaram impacto direto nos sistemas de produção foram representados na figura. Para as demais trajetórias de sistemas de produção, não foram elaboradas representações sintéticas; apenas serão discutidas as coerências, destacando-se as mudanças e como elas são processadas. 


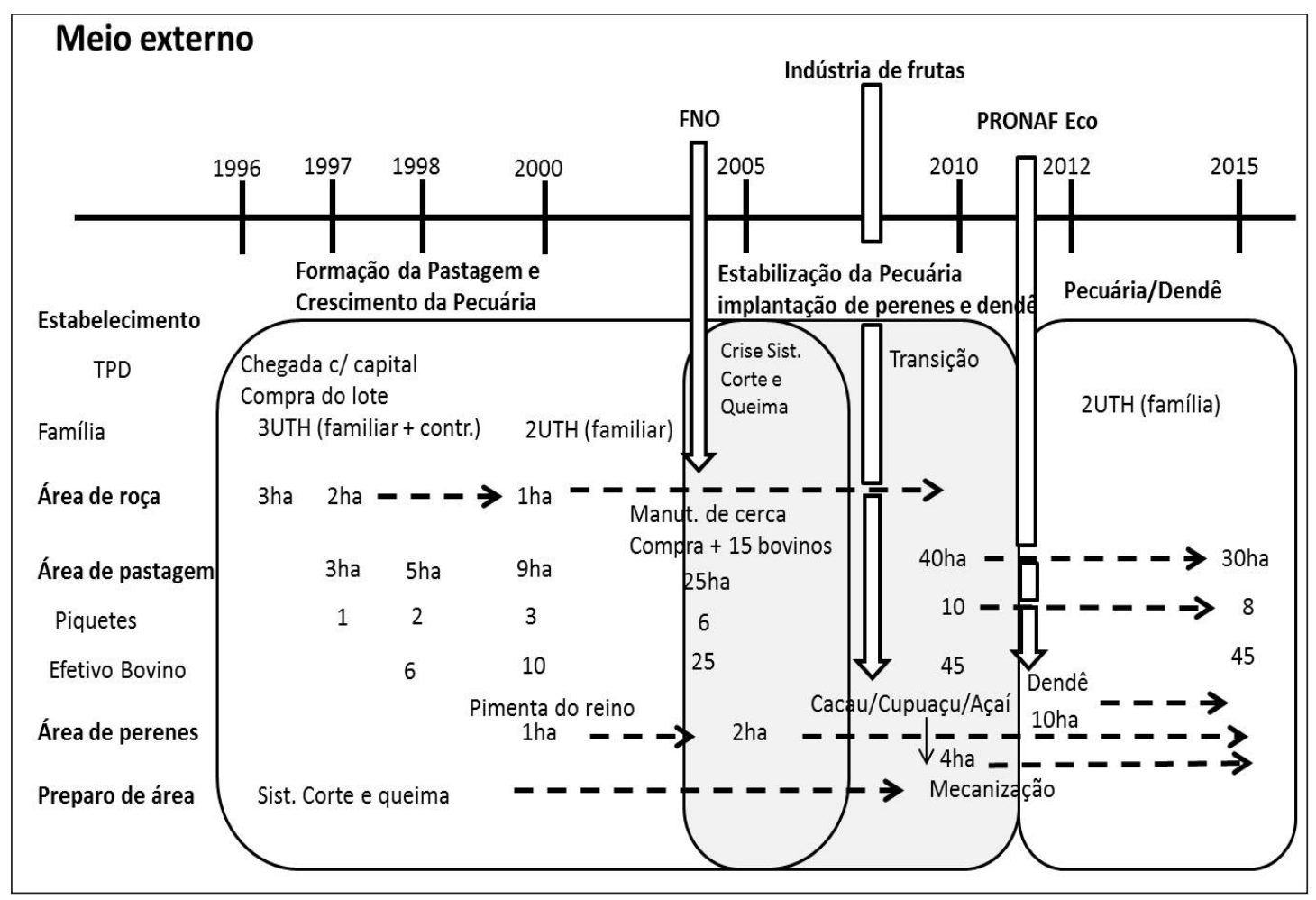

FIGURA 2 - Trajetória do tipo Pecuária/Dendê de um estabelecimento familiar integrado à dedeicultura no Nordeste Paraense. Nota: UTH (Unidade de Trabalho Homem) = 1 adulto, 8h/dia, em 300 dias trabalhados; TPD (Trajetória Pecuária/Dendê); FNO (Fundo Constitucional de Financiamento do Norte); ha (hectares); PRONAF ECO (Programa de Fortalecimento da Agricultura Familiar - Ecológico).

FONTE: da pesquisa (2015). Elaborado pelos autores.

Esse grupo é composto por aqueles agricultores que têm como estratégia principal de estabilização dos sistemas de produção a criação de bovinos. O estabelecimento escolhido para ilustrar esse caso se inicia em 1996. Logo na chegada, o agricultor faz uma roça de três hectares, que, para os padrões da região, é relativamente grande, visto que a média é de 1,5 hectares. A estratégia de fazer as roças é para preparar a área para o plantio das pastagens, segundo Walker et al. (1998). Entre os agricultores que buscam se estabilizar via criação de bovinos, essa é uma prática comum.
A formação do pasto ocorreu até 2010, quando também se parou de fazer as roças. Pouco antes, entre 2007 e 2008, foram realizadas lavouras de frutíferas, tendo em vista a possibilidade da venda de polpa de frutas para uma agroindústria de frutas que se instalou na região. Assim, começou-se a cultivar perenes no estabelecimento, a fim de se atingir um projeto de consolidação por meio da pecuária e de perenes. Para os agricultores, a implantação da dendeicultura, em 2010, foi a possibilidade de se atingir tal projeto, pois o dendê veio acompanhado de um pacote (crédito, mecanização, adubos sintéticos, agrotóxico e mercado garantido por contrato) 
que poderia viabilizar tal consolidação dos estabelecimentos projetados pelos agricultores.

Pôde-se verificar que, após a formação completa da área de pasto desejada, os agricultores pararam de fazer as roças. Entretanto, foi possível, também, observar que não foi apenas o fato de atingir o tamanho de pasto ideal que levou os agricultores a não mais cultivarem anuais. A crise no sistema técnico (corte e queima), com a diminuição dos pousios, e a crise no sistema de cultivo da mandioca, com severa incidência de podridão mole das raízes, bem como a entrada da dendeicultura, foram fundamentais na inviabilização das roças. Os agricultores priorizaram os dendezais em detrimento das roças, principalmente, por falta de mão de obra e redução de áreas por destinação de parte da terra às lavouras de dendê.

Na trajetória Pecuária/Dendê, verificou-se que os agricultores implantaram a dendeicultura em áreas de pasto degradado. Com a aplicação de adubação sintética na cultura do dendê, as pastagens se recuperaram, e os agricultores colocaram o rebanho bovino para se alimentar dessa pastagem. De tal modo, observou-se que, apesar da redução da área de pasto, parcialmente disponibilizada para parcela de dendê, o número do rebanho não diminuiu, o que poderia indicar intensificação nas práticas, mas, nesse caso (ilustrado na Figura 2), verificou-se que o agricultor optou por aproveitar a recuperação da pastagem, entre as linhas do dendezal, para colocar os bovinos para pastejar. No entanto, essa estratégia pode ser limitada, pois, a partir do sétimo ano, o dendê começa a fechar a copa, e as pastagens não resistirão ao intenso sombreamento.

\subsubsection{Trajetória Anuais/Dendê}

Esse tipo de trajetória é a mais representativa dos sistemas de produção do Nordeste Paraense.
As culturas anuais, principalmente a mandioca, têm um papel fundamental na reprodução social dos agricultores familiares dessa região, como destacam Conceição (2002) e Hurtienne (2005). Isso porque essa cultura serve tanto para alimentação como para geração de renda, com a venda da farinha de mandioca.

Também, a mandioca pode ficar um pouco mais na terra, esperando a melhoria de preço, o que dá maior liberdade ao agricultor de fazer escolhas, de comercializar a produção ou esperar. Sendo assim, é uma cultura que possibilita a condição de alternatividade, conforme Garcia-Júnior (1983). Isso também é possível com a farinha de mandioca, pois, se armazenada em ambiente seco e em embalagem vedada, não sofre ação de micro-organismos, tornando-se não perecível. No entanto, se exposta à umidade, tem um prazo de validade de 90 dias (Bezerra, 2006).

$\mathrm{Na}$ fase de inicial do sistema de produção dessa trajetória, a família vai criando relações com mercados, por meio da comercialização da farinha de mandioca. Normalmente, a produção é vendida para atravessadores, feirantes e supermercados de centros urbanos próximos às localidades onde os agricultores se instalam. Esse tipo de organização de relações de mercado estimula a continuidade do sistema de cultivo da mandioca, que é repetido ano após ano.

Com o passar do tempo, os agricultores vão se aprimorando, conhecendo melhor o ambiente local e desenvolvendo técnicas, como a realização de dois tipos de roça em períodos diferentes, para ter produção suficiente tanto para o consumo quanto para a venda no mercado local. Assim, os agricultores, normalmente, fazem duas plantações de culturas anuais em períodos distintos, chamadas por eles de roças de inverno e verão. 
Essa técnica de plantar no período seco tem a ver, segundo os agricultores, com a severidade da podridão mole das raízes, pois, quando se planta no verão, a incidência de fungos é menor, e, pelo fato de a mandioca ser de variedades de ciclo mais curto, evitam-se maiores perdas pelo menor tempo de exposição ao fungo. Na roça convencional, as raízes são colhidas entre 12 a 18 meses, e, por ficar um tempo maior no solo, a chance de perda da produção é alta. No entanto, o tamanho das raízes nas roças de verão é menor que nas de inverno, motivo que impulsiona os agricultores a ainda fazerem as roças de inverno.

Esses resultados revelam um importante saber-fazer, que tem garantido a reprodução dos agricultores familiares no Nordeste Paraense, onde o cultivo da mandioca tem sido central. Woortmann \& Woortmann (1997) consideram a produção central para reprodução do grupo doméstico. Para eles, é pelo trabalho que se constrói a família, e é pelo saber "técnico" que se tem o controle sobre a organização e gestão dos estabelecimentos. Isso é passado de geração a geração, como têm feito os agricultores na região.

Verificou-se que, na Fase 2 dessa trajetória (Anuais/Dendê), os estabelecimentos passam por uma crise no sistema técnico de corte e queima e enfrentam dificuldades com o mercado muito incerto, com constantes flutuações do preço da farinha de mandioca. Outra questão está relacionada com os problemas sanitários, principalmente a podridão mole das raízes, que fez com que os agricultores perdessem mais de $60 \%$ das lavouras em determinados anos. Nesse sentido, essa fase representa uma situação de crise no projeto das famílias. Sobretudo para esses agricultores, o dendê é compreendido como a única alternativa para se estabilizarem.

Na Fase 3, observa-se a implantação da dendeicultura nos lotes familiares. A cultura do dendê é tida como uma atividade que pode viabilizar o projeto de consolidação dos estabelecimentos. Isso implica uma reorganização da mão de obra familiar, visto que as parcelas de dendê são maiores, em comparação com as das culturas anuais e, para as atividades mais penosas, como a colheita dos cachos de dendê, as famílias contratam mão de obra externa ao lote.

O trabalho no dendê, bem como a diminuição da área de pousio para realização das roças, são os principais fatores que influenciam a interdição ou redução no tamanho das áreas de roças, como se argumentou mais acima. Portanto, verificou-se uma tendência nessa trajetória (Anuais/Dendê) para uma especialização na dendeicultura; em $24 \%$ dos estabelecimentos, constatou-se o abandono completo das culturas anuais.

\subsubsection{Trajetória Perenes/Dendê}

Nessa trajetória, o projeto da família, desde a chegada, era estabilizar o sistema de produção por meio de cultivos perenes. No início, podem ser realizadas roças pequenas (de até 1 hectare) para garantir as necessidades básicas de alimentação da família com a produção de arroz, feijão, farinha de mandioca, abóbora (Cucurbita pepo) e outros. Estratégia similar foi observada por Rocha (2016), na Microrregião de Altamira, no Estado do Pará.

O tipo de trajetória Perene/Dendê pode ser dividido em dois subtipos: aqueles voltados à formação dos pimentais e os que se direcionam a formar os sistemas agroflorestais (SAF). Na região Nordeste Paraense, a cultura da pimenta do reino foi amplamente cultivada nos anos 1980 e 1990, mas, devido a problemas fitossanitários (fusariose), ocorreram muitas perdas, e vários pimentais foram dizimados pela doença, o que obrigou os agricultores a se endividarem nos bancos. Nesse contexto, os SAF surgiram como alternativa, sendo direcionados principalmente para a produção de frutas, como o cupuaçu, o cacau e o açaí (Homma, 2004). Na atua- 
lidade, há uma retomada do cultivo da pimenta do reino, diante da alta demanda do mercado.

Na região, os SAF surgem da extensão dos quintais, onde os agricultores vão inserindo espécies, principalmente frutíferas, para a alimentação da família, assim como para a comercialização da produção nos períodos de necessidade. Em Tomé-Açu, os agricultores, imigrantes japoneses, praticam com sucesso esse tipo de atividade, existente a mais de 40 anos (Kato et al., 2012). Nessa região, montaram uma cooperativa (Cooperativa Mista de Tomé-Açu - CAMTA) e instalaram uma agroindústria de processamento de frutas, a qual incentivou muitos agricultores a investirem nesse tipo de uso da terra.

Com a implantação do dendê, os agricultores têm a perspectiva de aumentar a diversificação produtiva - o que já fazia parte das estratégias nesse tipo de trajetória - e diminuir a vulnerabilidade da dependência de apenas uma cultura, para não repetirem os problemas vivenciados no auge do monocultivo da pimenta do reino.

A dendeicultura não muda a trajetória do tipo Perenes/Dendê, apesar de influenciar a organização produtiva em aspectos como uso de mão de obra e aumento do uso de insumos sintéticos e agrotóxicos. Nesse sentido, o projeto da família, baseado na consolidação dos estabelecimentos por meio de atividades permanentes, não é alterado, e a dendeicultura é vista pelos agricultores como uma atividade a mais, que pode contribuir com o processo de estabilização dos sistemas de produção em curso.

\subsection{Mudanças influenciadas pela} dendeicultura nos sistemas produção familiares

Verificou-se que a dendeicultura modificou as trajetórias daqueles agricultores que estavam se estabelecendo na pecuária e os que tinham a cultura da mandioca como atividade principal. No caso da pecuária, esta seguiu uma direção de pecuária/ dendê, não se verificando o abandono ou redução dos rebanhos bovinos em detrimento ao cultivo do dendê, isso porque a atividade pecuária necessita de pouca mão de obra, sendo uma pessoa capaz de lidar/manejar com todo o rebanho (Veiga et al., 2004).

Também, a área de pastagem em que foi plantada o dendê é utilizada para alimentação dos bovinos, pelo menos nos anos iniciais. No entanto, conciliar as duas atividades (a longo prazo) exigirá dos agricultores intensificação nas práticas de criação para poder manter o rebanho que já estava consolidado.

Por outro lado, verificou-se que desenvolver as roças anuais e cultivar o dendê implicam um maior uso de mão de obra que, normalmente, é solucionado com a contratação de terceiro, o que requer recursos financeiros. Os lotes, nesses sistemas de produção, têm tamanho médio de 25 hectares, o que limita o tempo de pousio, por redução das áreas suficientes para os rodízios no sistema de corte e queima. Desse modo, há uma tendência à especialização na dendeicultura e ao abandono ou diminuição das áreas de roças. Na Figura 3, pode-se observar as trajetórias dos sistemas de produção e as tendências de evolução destes.

Dos 162 agricultores entrevistados na pesquisa, $66 \%$ faziam roças de culturas anuais antes do dendê, enquanto, após a entrada do dendê, apenas $52 \%$ estão fazendo as roças. Na chegada, todos os estabelecimentos faziam anuais para garantir, principalmente, o consumo da família. Com a evolução dos sistemas de produção, vão ocorrendo mudanças, conforme discutido acima. Essas transformações são influenciadas tanto pelo projeto da família como pelas dinâmicas externas. As anuais só permanecem em um grupo de trajetória, e os dados 


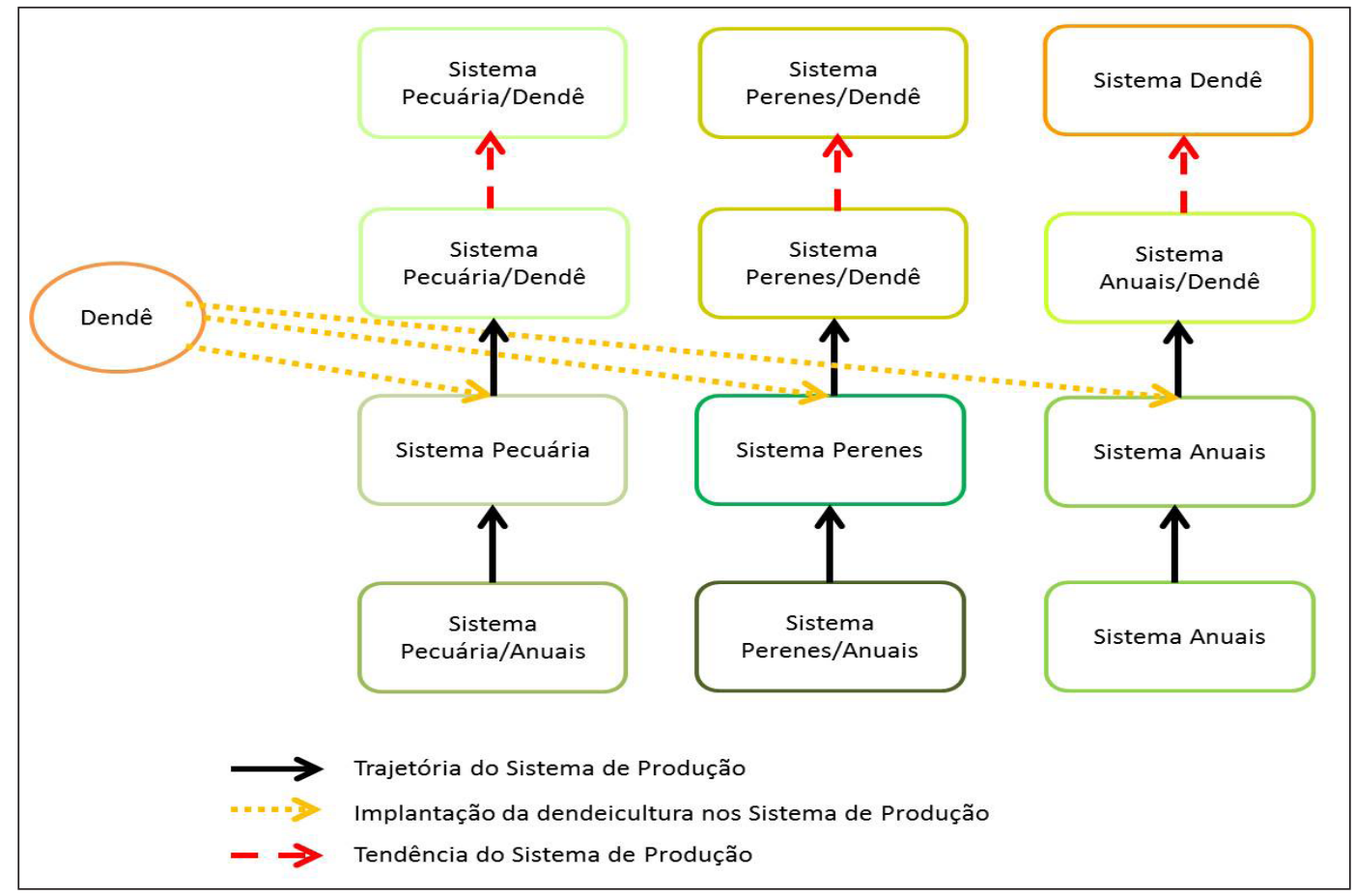

FIGURA 3 - Trajetórias e tendência de evolução dos sistemas de produção integrados às agroindústrias de dendê no Nordeste Paraense.

FONTE: da pesquisa (2015). Elaborado pelos autores.

revelam que esse tipo de atividade pode ser extinto dos sistemas de produção familiares que aderiram à dendeicultura.

A modalidade de agricultura por contrato traz para os agricultores a obrigatoriedade de inserção de novas práticas agrícolas, situadas no itinerário técnico que deve ser cumprido pelos agricultores, a exemplo de: limpeza da área, no mínimo, duas vezes ao ano; aplicação de adubo sintético; colheita quinzenal (a partir do quarto ano de plantio, quando o dendê está produzindo), entre outros.

A parcela de 10 hectares de dendê nos lotes dos agricultores foi preparada com uso de maquinários; 97\% dos agricultores utilizaram maquinários para realização de aração e gradarem, a maioria alugados.
Antes do dendê, apenas $10 \%$ faziam preparo de área com maquinários. A forma de preparo de área tradicional na região é o sistema técnico de corte e queima. Vale ressaltar que, para aqueles sistemas de produção em que as famílias ainda praticam as roças ( $52 \%$ dos entrevistados), o preparo de área ainda é feito por meio desse sistema técnico tradicional.

Partindo-se do pressuposto de que "toda prática humana combina uma dimensão objetiva e uma dimensão das representações" (Godelier, 1984 apud Raynaut, 1994 p. 83), a integração de agricultores familiares à agroindústria do dendê, para além do valor instrumental (novas práticas agrícolas), tem também um valor simbólico. Portanto, identificou-se que se integrar a uma agroindústria de dendê 
significou para os agricultores: 1) a permanência da família trabalhando na agricultura; 2) a segurança de mercado; 3) a possibilidade de uma renda contínua e; 4) o "moderno" - acesso à tecnologia e ao empreendedorismo.

Os agricultores relatam que o tempo de contrato de 25 anos é a possibilidade de garantir que a família continue na agricultura por mais tempo, haja vista os diversos entraves enfrentados pelos grupos domésticos no desenvolvimento dos sistemas de produção tradicionais. O que está por trás dessa questão é a vulnerabilidade das sociedades rurais no Pará, o que contribui para famílias abandonarem seus lotes, deixando a atividade agrícola para migrarem para as cidades em busca de condições melhores para sobreviver.

$\mathrm{O}$ fato de assinar um contrato com uma empresa de dendê, que se compromete a comprar a produção dos agricultores, representa a segurança de mercado que o sistema das anuais, baseado na produção de mandioca para farinha, não garante. A compra assegurada em contrato também representa uma renda contínua. Mesmo com variações nos preços pagos pela agroindústria, os agricultores têm a certeza de que venderão o que produziram e terão uma receita. Para Gazolla \& Schneider (2007), a lógica de produção e reprodução social dos agricultores familiares está assentada tanto no mercado como na produção para o autoconsumo. No caso das trajetórias Anuais/Dendê, que têm indicado uma especialização na dendeicultura, a produção para o aprovisionamento pode se extinguir.

A integração representa também o "moderno" na concepção dos agricultores, pois, como relata um agricultor entrevistado no Município de Tailândia: "A mandioca é atrasada, ainda na enxada, muito ruim. O dendê tem adubo, trator, tem indústria é moderno. Eu queria muito plantar dendê, até que veio o pessoal da Petrobrás dizer pra mim (sic) assinar o contrato com eles." (S. ${ }^{4}, 59$ anos, agricultor integrado). Desse modo, é como se o dendê fosse uma nova perspectiva de futuro, na qual os agricultores conseguiriam a consolidação dos estabelecimentos agrícolas, a permanência da família na agricultura e melhorias nas formas de produzir, graças ao acesso ao crédito, assistência técnica, uso de mecanização agrícola, adubos sintéticos e agrotóxicos.

\subsection{Evolução da dinâmica de uso da terra nos sistemas de produção}

No estudo, foram identificadas três dinâmicas de uso da terra (Figura 4). A dinâmica 1 (evolução do uso da terra da trajetória Pecuária/Dendê) é o modelo mais clássico de ocupação da terra e sucessão das atividades de interesse agropecuário na Amazônia Oriental. O principal antecedente vegetativo para implantação de cultivos, nessa dinâmica, é a floresta, fonte de aproveitamento do capital energético pelo corte raso e queima de sua vegetação. Após a queima da vegetação, são plantadas culturas anuais, em sistema consorciado com gramínea forrageira ou não, sendo, então, essas forrageiras, após sua colheita, introduzidas na sequência dos cultivos anuais.

Nessa dinâmica 1, o principal objetivo da família é formar pasto. As anuais têm o papel de fornecer produtos para o autoconsumo, principalmente na fase da chegada ao lote. Esse modelo de uso da terra é semelhante a outros observados em áreas de fronteira no Pará, como identificou Walker et al.

\footnotetext{
${ }^{4}$ Para preservar o anonimato dos entrevistados, optou-se por usar abreviações de seus nomes.
} 


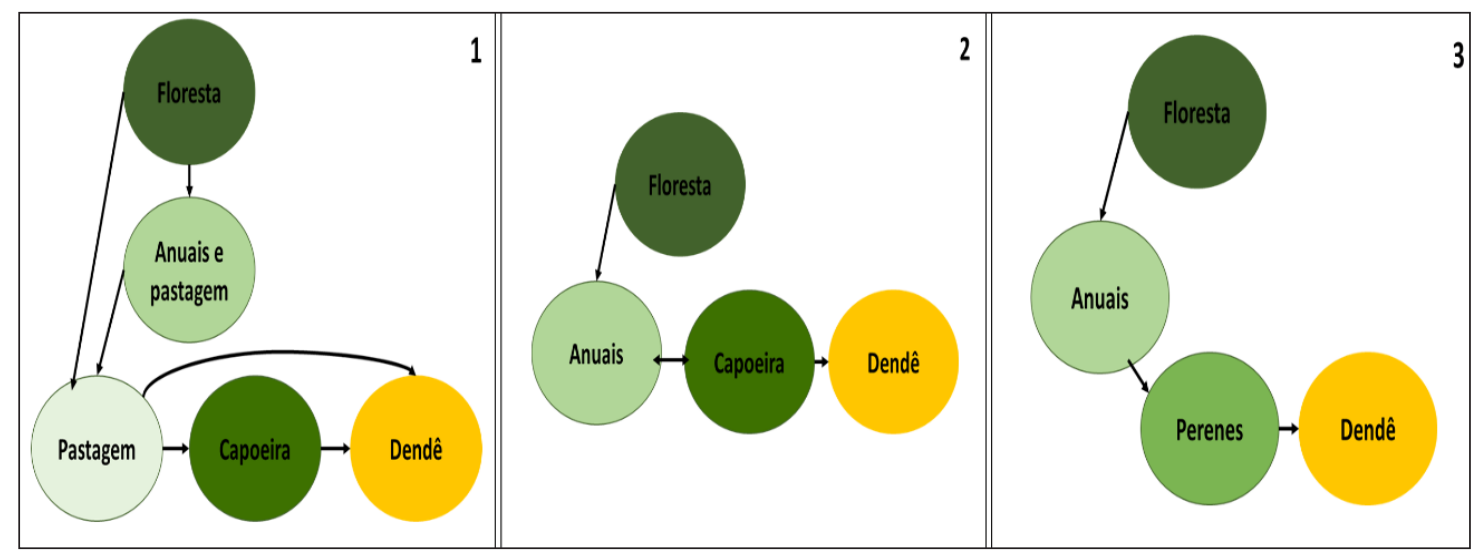

FIGURA 4 - Dinâmicas de evolução do uso da terra praticado por agricultores familiares no Nordeste Paraense. FONTE: da pesquisa (2015). Elaborado pelos autores.

(1998), na região de Marabá, e Rocha e Almeida (2013), na região de Altamira. A principal diferença está no fato de atualmente haver uma tendência no Nordeste Paraense de conversão de parte dos pastos em dendezais, ou seja, uma dinâmica de pastagens substituídas por perenes. Para Mello \& Théry (2001), essa dinâmica é um processo engendrado pelo Estado paraense, com o qual se fecha um ciclo: desmatamento - pecuária-agricultura capitalizada de exportação.

A dinâmica 2 é o modelo de conversão do uso da terra da trajetória Anuais/Dendê. Essa dinâmica representa um modelo no qual predomina o cultivo de anuais, com destaque para a cultura da mandioca. Para Conceição (2002), esse modelo agrícola é histórico, sucedeu várias tentativas de monocultivos (cana-de-açúcar, algodão...), conviveu com o extrativismo e gerou forte economia agrícola ligada aos comerciantes, marreteiros e feirantes dos centros urbanos, tornando-se a estratégia produtiva mais importante para a reprodução social da agricultura familiar no Nordeste Paraense. No entanto, com a chegada da dendeicultura, tem sido difícil manter as roças, sendo essas realizadas basicamente para o consumo da família.

A dinâmica 3 representa a trajetória Perenes/ Dendê. As culturas da pimenta do reino ou das frutíferas desempenharam importante papel na busca de consolidação dos estabelecimentos agrícolas. As culturas anuais podem aparecer no início, com o objetivo de ter produtos para o autoconsumo, principalmente o arroz e a farinha de mandioca. Esses estabelecimentos são bem representativos em locais onde os Sistemas Agroflorestais (SAF) são expressivos, como no Município de Tomé-Açu.

\subsection{A conformação de um ambiente favorável à dendeicultura}

O contexto favorável para a dendeicultura ser implantada nos estabelecimentos familiares na região do Nordeste Paraense pode ser explicado por fatores internos e externos aos sistemas de produção familiares. 


\subsubsection{Fatores externos}

Os fatores externos estão no meio envolvente ao sistema familiar de produção, como, por exemplo: mercado, políticas públicas e assistência técnica. Nesse estudo, foram identificados três principais fatores externos que influenciaram a decisão dos agricultores familiares de aderir ao plantio de dendê em seus lotes São eles:

1) As políticas públicas federais para os agrocombustíveis: o Programa Nacional de Produção e Uso do Biodiesel (PNPB, em 2004) e o Programa de Produção Sustentável de Palma de Óleo (PSOP, em 2010) foram fundamentais para expansão da dendeicultura na região do Nordeste Paraense, na medida em que criaram um ambiente favorável às empresas que se instalaram, fornecendo incentivos fiscais, facilitações para participações nos leilões públicos da Agência Nacional de Petróleo, Gás Natural e Biocombustíveis (ANP) e melhores condições (de financiamento dos cultivos e instalação das indústrias) junto aos bancos que operam o PNPB (MDA, 2011). O PSOP foi mais incisivo por ser um programa específico para a dendeicultura e principalmente por estabelecer o PRONAF Eco - um financiamento exclusivo para agricultores familiares produzirem dendê (financiando até $\mathrm{R} \$ 80$ mil para cada família).

A entrada de novas empresas no setor da dendeicultura na região do Nordeste Paraense é um subfator do fator externo 1 (políticas federais para os agrocombustíveis). Verificou-se que, a partir de 2007, várias empresas chegaram à região, interessadas na cadeia produtiva do dendê. Algumas delas sem tradição na produção de dendê, como, por exemplo, o grupo Vale do Rio Doce, do setor de extração de minério, que adquiriu 70\% (em 2011) da empresa canadense Biopalma, e as empresas Petrobrás (estatal brasileira) e PPBio (empresa Portugue- sa), que se juntaram para formar a empresa Belém Bioenergia do Brasil (BBB). A chegada de novas empresas iniciou uma intensa busca por integrar agricultores familiares as suas cadeias produtivas, tendo em vista que os benefícios oferecidos pelos programas federais para agrocombustíveis, descritos acima, têm como um dos critérios a participação de agricultores familiares como fornecedores de matéria-prima (até 15\% da matéria-prima fornecida à indústria deve vir da agricultura familiar).

2) A pressão ambiental para redução do uso do fogo: em 2008, a operação Arco de Fogo fechou várias madeireiras nos Municípios de Moju, Tailândia e Tomé-Açu e também pressionou as prefeituras e o governo estadual a reduzirem as queimadas. Dessa forma, vários agricultores familiares foram multados pelas secretarias de meio ambiente municipais e estadual no Nordeste Paraense. A dendeicultura despontou então como a solução para que os agricultores continuassem a produzir, uma vez que, para essa atividade, há a disponibilização de maquinários - subsidiados por meio de financiamentos - para preparo das áreas, em substituição ao uso do fogo. De forma diferente acontece com a produção tradicional da região, como a farinha, que não tem financiamento e nem apoio para que todos os agricultores possam mecanizar suas áreas; além do que, dependendo das oscilações do valor de mercado, os custos podem não compensar seu emprego. Os tratores e implementos normalmente pertencem às empresas, às instituições estaduais (especialmente a Secretaria de Agricultura do Estado do Pará - SAGRI) e às associações, sindicatos e cooperativas que receberam máquinas doadas pela SAGRI.

3) O mercado incerto para produtos tradicionais: apesar da forte demanda pela farinha de mandioca no Pará, o mercado é bastante incerto para os agricultores familiares. Normalmente, a 
produção é vendida a atravessadores, que pagam um preço muito baixo, o que faz com que, para muitas famílias, a produção de farinha para o mercado não seja compensatória. Pode existir uma importante oscilação de preço da farinha de mandioca entre os anos (da ordem de mais de $100 \%$ do valor), o que ocorre, geralmente, de maneira cíclica. Por outro lado, as dificuldades de escoamento da produção, diante das distâncias e precariedade das estradas, tornam ainda mais difícil a comercialização da produção. Diferentemente da farinha de mandioca, a produção de cachos de fruto fresco de dendê tem comprador certo, garantido em contrato, por meio do qual a empresa integradora se compromete em comprar a produção do agricultor e, muitas vezes, ir buscar a produção na porta da propriedade, garantindo maior segurança.

\subsubsection{Fatores internos}

Os fatores internos aos estabelecimentos agrícolas que podem contribuir para mudanças (ou para a tomada de decisões que levam a mudanças) são aqueles que dizem respeito ao estabelecimento (infraestrutura, recursos disponíveis...) e aos aspectos da família (projeto de vida da família, mão de obra...). O principal fator interno observado nesse estudo foi a crise nos sistemas técnicos de corte e queima e de cultivo da mandioca:

1) Crise do sistema técnico de corte e queima e no sistema de cultivo de mandioca: do universo estudado, quase $90 \%$ dos agricultores apontaram os problemas ligados a esse sistema de corte e queima como um dos principais entraves para fazer as roças anuais. A limitação imposta a esse sistema técnico tem a ver com o esgotamento da fertilidade dos solos (Piraux et al., 2014), provocada pelo aumento demográfico excessivo que leva ao uso de novos trechos na mesma área, sem tempo para pousio (Conceição, 2002; Hurtienne, 2005).

A podridão das raízes de mandioca foi o principal problema fitossanitário apontado pelos agricultores nesse estudo: $27 \%$ afirmaram que já tiveram perdas totais das lavouras, enquanto os demais chegam a perder mais de $40 \%$ dos plantios, o que inviabiliza a produção comercial. Identificaram-se as maiores incidências da podridão mole das raízes de mandioca nos Municípios de São Domingos do Capim e Acará (atingindo-se 100\% das roças). Esse problema fitossanitário é causado por fungos dos gêneros Phytophthorae Pythium. As espécies mais comuns identificadas na região são Phytophthora drechsleri Tucker, P. nicotianae Breda de Haan, P. richardiae Buisman e Pythium scleroteichum Drechsler (Poltronieri et al., 1993; 1997).

Portanto, para os agricultores entrevistados nessa pesquisa, os fatores externos e internos elencados aqui conformaram um ambiente favorável para a decisão de implantar o dendê em seus lotes. Desse modo, a dendeicultura foi apresentada como a solução dos problemas vivenciados pelos agricultores. Esse reconhecimento se deve ao fato de que essa cultura vem acompanhada de um pacote tecnológico que disponibiliza maquinários para preparo de área (eliminando o fogo), adubação química para manter o desenvolvimento da cultura, agrotóxico para os problemas fitossanitários, além de crédito agrícola, assistência técnica e comercialização para indústria firmada em contrato.

\section{Considerações finais}

A implantação da dendeicultura nos sistemas de produção familiares influenciou mudanças tanto práticas como simbólicas. No que diz respeito às práticas, pôde-se observar que os agricultores in- 
tensificaram o uso de maquinários para preparo de área, adubação sintética para o desenvolvimento da cultura do dendezeiro, agrotóxico para o controle fitossanitário, além de contratarem mais mão de obra. Também, verificou-se a interdição e/ou diminuição das áreas de roças.

No campo simbólico, a dendeicultura representa uma nova perspectiva de futuro, com base na qual a família vislumbra permanecer na agricultura. Ademais, o dendê figura no imaginário dos agricultores como sinônimo de "modernidade", por trazer tecnologias agrícolas, industrialização da produção agrícola, entre outros fatores. A produção de dendê por meio de contrato de integração também traz garantia de mercado que as culturas tradicionais não asseguram, bem como uma renda contínua.

A dendeicultura foi implantada nos estabelecimentos familiares no Nordeste Paraense porque se conformou um contexto favorável à expansão do dendê, determinado por fatores internos e externos. A crise no sistema técnico e no sistema de cultivo da mandioca foram os principais fatores internos que

\section{Referências}

ABRAPALMA - Associação Brasileira de Produtores de Óleo de Palma. Planilha de mapeamento da palma de óleo no Brasil, 2014.

Backhouse, M. A desapropriação sustentável da Amazônia: o caso de investimentos em dendê no Pará. Berlin: FarFuels Working Paper 6, 2013.

Bezerra, V. S. Farinha de mandioca seca e mista. Brasília: Embrapa Informação Tecnológica, 2006. Disponível em: <http://ainfo.cnptia.embrapa.br/digital/bitstream/ item/11874/2/00079010.pdf $>$.

Brondízio, E. Intensificação agrícola, identidade econômica e invisibilidade entre pequenos produtores rurais amazônicos: caboclos e colonos numa perspectiva comparada. In: contribuíram para a decisão de aderir ao sistema de integração proposto pelas empresas de dendê. As políticas públicas no âmbito dos agrocombustíveis foram as forças propulsoras que induziram as empresas de dendê a procurarem agricultores familiares para assinarem os contratos de integração.

Por fim, conclui-se que a implantação da dendeicultura nos sistemas de produção familiares influenciou mudanças objetivas (e subjetivas) na condução dos estabelecimentos e significou, para os agricultores, a possibilidade de melhorar suas condições de vida. Não obstante, para a maioria (66\%), há o risco de ficar dependente da cultura do dendê. A atividade dendeícola não tem o mesmo caráter de alternatividade que a cultura da mandioca, a qual, além de servir ao consumo e geração de renda, pode ficar na terra por um tempo a mais, esperando melhoria de preço, ou, no caso da farinha, ser armazenada com o mesmo objetivo. Sendo assim, de certa forma, a produção de mandioca possibilita mais liberdade de escolha para os agricultores do que a cultura do dendê.

Adams, C.; Murrieta, R.; Neves, W. (Orgs.). Sociedades caboclas amazônicas: modernidade e invisibilidade. São Paulo: Annablume, 2006. p. 195-236.

Brossier, J. Système et système de production: note sur ces concepts. Cahiers des Sciences Humaines, 23(3-4), 377-390, 1987. Disponível em: <http://horizon.documentation.ird.fr/ exl-doc/pleins_textes/pleins_textes_4/sci_hum/24935.pdf>

Capillon, A. Typologie des exploitations agricoles, contribution à létude régionale des problèmes techniques. 48 p. Tese (Doutorado) - Institut National Agronomique de Paris-Grignon, Paris-França, 1993.

Conceição, M. F. C. Reprodução social da agricultura familiar: um novo desafio para a sociedade agrária do Nordeste 
Paraense. In: Hébette, J.; Magalhães, S. B.; Maneschy, M. C. No mar, nos rios e na fronteira: faces do campesinato no Pará. Belém: EDUFPA, 2002. p. 133-171.

Ellis, F. Rural livelihoods and diversity in developing countries. Oxford: Oxford University Press, 2000.

Garcia-Júnior, A. R. Terra de trabalho: trabalho familiar de pequenos produtores. Rio de Janeiro: Paz e Terra, 1983.

Gazolla, M.; Schneider, S. A produção da autonomia: os "papéis" do autoconsumo na reprodução social dos agricultores familiares. Estudos Sociedade e Agricultura, 15(1), 89-122, 2007. Disponível em: <http://r1.ufrrj.br/esa/V2/ojs/ index.php/esa/article/viewFile/283/279>

Homma, A. K. O. Dinâmica dos sistemas agroflorestais: o caso da Colônia Agrícola de Tomé-Açu, Pará. Revista Instituto de Estudos Superiores da Amazônia, 2, 57-65, 2004. Disponível em: < https://ainfo.cnptia.embrapa.br/digital/ bitstream/item/82552/1/080395.pdf>

Hurtienne, T. Agricultura familiar e desenvolvimento rural sustentável na Amazônia. Novos Cadernos do NAEA, 8(1), 19-71, 2005. Disponível em: <http://periodicos.ufpa.br/ index.php/ncn/article/viewFile/47/42>

IBGE - Instituto Brasileiro de Geografia e Estatística. Pesquisa Agrícola Municipal, 2015. Disponível em: <http:// www.sidra.ibge.gov.br/bda/acervo/acervo2.asp? $=\mathrm{v} \& \mathrm{p}=\mathrm{L}-$ $\mathrm{T} \& \mathrm{z}=\mathrm{t} \& \mathrm{o}=24>$. Acesso em: dez. 2015.

Kato, O. R. et al. Desenvolvimento da produção de frutas em sistemas agroflorestais no Estado do Pará. In: Anais do XXII Congresso Brasileiro de Fruticultura. Bento Gonçalves, 2012. Disponível em: <https://www.alice.cnptia. embrapa.br/alice/bitstream/doc/950198/1/Painel12OsvaldoKato.pdf $>$.

MDA - Ministério do Desenvolvimento Agrário. O Selo Combustivel Social, 2011. Disponível em: <http://www. mda.gov.br/sitemda/secretaria/saf-biodiesel/o-selo-combust $\% \mathrm{C} 3 \%$ ADvel-social\#sthash.F5xeBIGi.dpuf $>$. Acesso em: jan. 2016.

Mello, N. A.; Théry, H. A armadura do espaço amazônico: eixos e zoneamentos. ALCEU, 1(2), 181-214, 2001. Disponível em: $<$ http://revistaalceu.com.puc-rio.br/media/ alceu_n2_Mello\%20e\%20Thery.pdf>

Mota, D. M. Família e grupo doméstico na Amazônia Paraense. Cadernos de Ciência \& Tecnologia, 31(2), 289-314,
2014. Disponível em: $<$ https://seer.sct.embrapa.br/index. php/cct/article/view/20865/12819>

Mota, M. D.; Silva, E. M.; Schmitz, H.; Navegantes-Alves, L.; Ferreira M. S. G. Produção de culturas alimentares e dendê nos estabelecimentos familiares no Nordeste Paraense. In: Anais Seminário Internacional América Latina: política e conflitos contemporâneos. Belém, 2015.

Moulin, C. H.; Ingrand, S.; Lasseur J.; Madelrieux S.; Napoleone, I.; Pluvinage, M. J.; Thenard, V.Comprendre et analyser les changements d'organisation et deconduite de l'élevage dans un ensemble d'exploitations :propositions méthodologiques. In: Dedieu, B.; Chia, E.; Leclerc, B.; Moulin, C. H.; Tichit, M. (Org.). L'élevage en mouvement: flexibilité et adaptation des exploitations d'herbivores. Paris: Quae, 2008. p. 181-196.

Moulin, C. H.; Pluvinage, J.; Bocquier, F. Les relations entre agrandissement des troupeau et changements de condute: exemple des élevages d'ovins allaitants en Crau. In: Anais... Rencontres Recherches Ruminants, 11., Paris, 2004. Disponível em: <http://www.journees3r.fr/IMG/ pdf/2004_agrandissement_04_Moulin.pdf>

Muller, A. A.; Viegas, J. M.; Celestino Filho, P.; Souza, L. A.; Silva, H. M. Dendê - problemas e perspectivas na Amazônia. Belém: Embrapa Amazônia Oriental. Documentos, 13,1989. 19 p. Disponível em: $<$ https://www.infoteca.cnptia. embrapa.br/bitstream/doc/379302/1/BelemDoc13.pdf $>$

Nahum, J. S.; Malcher, A. T. C. Dinâmicas territoriais do espaço agrário na Amazônia: a dendeicultura na microrregião de Tomé-Açu (PA). Confins, 16, 2012. Disponível em: $<$ https://confins.revues.org/7947?lang=pt $>$

Navegantes-Alves, L.; Poccard-Chapuis, R.; Ferreira, L. A.; Moulin, C. H. Transformações nas práticas de criação de bovinos mediante a evolução da fronteira agrária no Sudeste do Pará. Cadernos de Ciência \& Tecnologia, 29(1), 243-268, 2012. Disponível em: <http://seer.sct.embrapa.br/ index.php/cct/article/view/14550>

Piraux, M.; Cialdella, N.; Poccard, R.; Assis, W. S. O futuro incerto da agricultura familiar na Amazônia brasileira: um desafio para territórios e políticas públicas. In: Anais I Seminário Internacional de Desenvolvimento Rural Sustentável e IX Fórum Internacional de Desenvolvimento Territorial - Agricultura Familiar: ruralidade, território e política pública, Fortaleza, 2014. 
Poltronieri, L. S., Trindade, D. R., Silva, H. M.; Albuquerque, F. C. Patógenos associados à podridão mole de raízes de mandioca no estado do Pará. Fitopatologia Brasileira, 22(1), 111, 1997.

Poltronieri, L.S.; Trindade, D. R.; Silva, H. M. Podridão mole de raízes de mandioca induzida por Phytophthora drechsleri e Phytophthora nicotianaevar parasitica no Estado do Pará. Fitopatologia Brasileira, 18, 282, 1993.

Raynaut, C. O desenvolvimento e as lógicas da mudança: a necessidade de uma abordagem holística. Desenvolvimento e Meio Ambiente, 1, 81-104, 1994.

Raynaut, C. Sahels: diversité et dynamiques des relations sociétes-nature. Paris: Karthala, 1997.

Rocha, C. G. S. Reprodução social e práticas socioprodutivas de agricultores familiares do Pará. Jundiaí: Paco Editorial, 2016.

Rocha, C. G. S.; Almeida, J. Lógicas de reprodução social, trajetórias produtivas e gestão do meio natural de agricultores familiares no Sudoeste do Pará, Brasil. Novos Cadernos NAEA, 16(1), 140-172, 2013. doi: 10.5801/ncn.v16i1.988
Sampaio, I. C. A agricultura familiar e a agroindústria do dendê em Tomé-Açu (PA): efeitos da agricultura por contrato na produção e no trabalho familiar. Belém, Dissertação (Mestrado em Sociologia) - UFPA, 2014.

Veiga, J. B.; Tourrand, J. F.; Piketty, M. G.; Poccard-Chapuis, R.; Alves, A. M.; Thales, M. C. Expansão e trajetórias da pecuária na Amazônia. Brasília: Editora UnB, 2004.

Walker, R. T.; Homma, A. K. O.; Scatena, F. N.; Conto, A. J.; Rodrigues-Pedraza, C. D.; Ferreira, C. A. P.; Oliveira, P. M.; Carvalho, R. A.; Santos, A. J. M.; Rocha, A. C. P. N. A evolução da cobertura do solo nas áreas de pequenos produtores na Transamazônica. In: Homma, A. K. O. (Ed.). Amazônia: meio ambiente e desenvolvimento agrícola. Brasília: Embrapa - SPI, 1998. p. 321-343.

Wanderley, M. N. B. O mundo rural como espaço de vida: reflexões sobre a propriedade da terra, agricultura familiar e ruralidade. Porto Alegre: Editora da UFRGS, 2009.

Woortmann, E. F.; Woortmann, K. O trabalho da terra: a lógica e a simbólica da lavoura camponesa. Brasília: Editora $\mathrm{UnB}, 1997$. 